\title{
Media and Cultural Industries Internships: A Thematic Review and Digital Labour Parallels
}

\author{
Thomas F. Corrigan \\ California State University-San Bernardino, San Bernardino, USA, corrigan@csusb.ed
}

\begin{abstract}
This article reviews existing research on the motivations and experiences of interns in media and cultural industries. Digital labour theories are used to organize and make sense of the existing internship literature. Throughout the article, parallels are also drawn between the experiences of interns and those of digital creative labourers-both professionals and peer producers. Three key themes are identified within the internship literature: 1) interns derive satisfaction from work they consider meaningful, particularly hands-on work executed under the training and trust of effective supervisors; 2) interns see their work as future-oriented investments in their skills, professional networks, and personal brands; and 3) the ambiguity and professional necessity of media and cultural industries internships make them fertile ground for exploitation and self-exploitation. In conclusion, I argue that attentiveness to meaning, temporality, and ambiguity will be essential to future critical investigations of internships.
\end{abstract}

Keywords: media and cultural industries, internships, motivations and experiences of interns, digital labour

Acknowledgement: Thank you to the reviewers and special issue editors for their detailed feedback.

Ross Perlin's Intern Nation (2012) details an ingrained contemporary internship economy in which students "earn nothing and learn little"; however, many interns see this systemrelatively new as it is - as a valuable and necessary route to employment, particularly in media and cultural industries. Interns' motivations and understandings of their experiences are fundamental to the perpetuation of internships. After all, many students are not paid during their media and cultural industries internships (Jenkins 2003), so they must participate in these arrangements for reasons beyond an immediate paycheck.

This article offers a thematic review of scholarship on the motivations and experiences of interns working in media and cultural industries. Researchers often note a dearth of scholarly attention to interns' experiences (e.g., Daugherty 2011; Neff and Arata 2007); however, more literature exists than is typically acknowledged, and what does exist is instructive. Previous findings show that students evaluate their internships quite favourably. This is especially so when supervisors train and trust them to execute hands-on work, which they consider meaningful. Students also view internships as a means of increasing their future employment prospects through skill acquisition, expansion of professional networks, and crafting a personal brand. With few alternatives for gaining crucial work experience and networking, though, internships in the media and cultural industries are fertile ground for exploitation and selfexploitation. Many internships are unpaid, menial work is not uncommon, and supervisors can be indifferent to their interns' experiences. What an internship should entail is ambiguous, so interns seek to secure more meaningful, professionally promising work responsibilities by demonstrating their initiative and enthusiasm-even for menial tasks. Interns also find a silver lining in the most disappointing of circumstances.

To construct this review of the existing internship literature, this article uses digital creative labour-both professional and peer production-as a point of comparison. As Perlin (2012) writes, "The position of interns is not unlike that of many journalists, musicians, and filmmakers, who are now expected to work online for no pay as a way to boost their portfolios" (125). The parallels between internships and digital creative labour are not perfectly congruent; however, both groups do engage in complex and contradictory labour processes that are marked by personal and social pleasures, the pursuit of (potential) employment prospects, 
and (self-)exploitation. This article does not draw these parallels simply for comparison's sake, though: the theorizations of digital labour scholars provide fruitful frameworks for understanding interns' motivations and experiences. Whereas existing internship research tends to pursue "administrative" goals (e.g., assessing and improving intern satisfaction), many digital labour scholars take a more "critical" approach (Lazarsfeld 1941); they interrogate the ways in which digital labour reproduces or challenges power asymmetries. Thus, this article uses the critical frameworks of digital labour theorists to organize and make sense of the more administrative findings of existing internship research. Ultimately, I argue that the emerging area of critical internship studies must account for the meaning, temporality, and ambiguity of internships.

Before undertaking this analysis, the following section provides a brief overview of digital labour scholarship. I then explain my approach to thematically analyzing the existing internship research, and I offer a few cautionary notes about that literature.

\section{Delimiting Digital Creative Labour}

This article uses theories of digital creative labour to organize and make sense of interns' motivations and experiences; however, what is and is not "digital labour" is a matter of considerable debate (Fuchs and Sandoval 2014; Huws 2013; Scholz 2013). One debate concerns the range of productive processes classified as digital labour. The symbolic work of graphic designers, online journalists, transmedia storytellers, and other digital "creatives" certainly deserves attention. Their involvement in the "communication of experience through symbolic production" means that these labourers have an unusual capacity to shape society through information, entertainment, and persuasion (Hesmondhalgh and Baker 2011, 60-61). Alternatively, some scholars argue for conceptions of digital labour that account for a wider range of productive roles along the digital value chain (Fuchs and Sandoval 2014; Mosco and McKercher 2008). Slaves mining resources for smartphones, factory workers assembling those phones, software project managers working on app rollout, and telecommunications workers upgrading cell towers: is all this work not digital labour?

Digital media's interactivity also means that media consumers are increasingly producers, too, expanding the universe of public symbol-creators from the professional creatives just noted to countless "prosumers" (Ritzer and Jurgenson 2010) and "pro-ams" (Leadbeater and Miller 2004). Most digital media users engage in creative production for the fun of it (Arvidsson 2008), but that does not stop corporations from trying to monetize their creative work or the audience attention it generates (Baker 2008; Murdock 2011; Zwick, Bonsu and Darmody 2008). Our clicks, searches, purchases, and posts also produce marketing data that are valuable to web firms and corporate advertisers (Turow 2011). These productive activities may not be "labour" in its "quintessential," waged form (Huws 2013); however, the commercial appropriation and monetization of prosumers' content, audience attention, and marketing data still make "labour" a useful concept for understanding digital media users' relationships to digital capitalism (Andrejevic 2009; Cohen 2008; Fuchs 2012).

A second set of debates concerns the lived experience of digital labour. People use digital tools to collaboratively code software, write about sports teams, and edit countless Wikipedia entries, among a host of other "peer production" activities (Benkler and Nissenbaum 2006). Should this production-carried out primarily for personal and social pleasures rather than pay-be regarded as "labour" in the same way a professional software coder or journalist's work is? (Or, for that matter, a factory worker assembling smartphones?) On the one hand, this "free labor" (Terranova 2000) is consistent with Marxist models of capitalist value creation: in harnessing peer production online, corporations can avoid paying creators for the full value such activity produces, driving capital accumulation and, ultimately, class antagonisms. As George Ritzer and Nathan Jurgenson (2010) write, "From the capitalist's point of view ... the only thing better than a low-paid worker is someone (the consumer as prosumer) who does the work for no pay at all" (26). On the other hand, Mark Andrejevic (2009) points out that this digital labour is also "free" in that it is "freely given, endowed with a sense of autonomy" (416). People engage in peer production for the pleasure of creating on their own terms 
in a community of others who share their interests (Arvidsson 2008; Shirky 2010). These freely given, pleasurable production experiences clash with Marxist formulations of labour exploitation as coercive and alienating. And these contradictions have led to novel theorizing, including the concepts of "playbour," or the fusion of play and labour (Kücklich 2005), and the pro-am, remembering that "amateur" derives from amor. Similarly, pleasure and (self-)exploitation also co-mingle in professional digital creative work (Hesmondhalgh and Baker 2011; Ross 2003; Neff 2012).

While acknowledging digital labour's contested status, in this article I selectively draw on scholarly examinations of a subset of digital labour: creative, public symbol-making carried out in professional and peer production contexts. The labour of miners, factory workers, and others not directly involved in crafting public, symbolic texts is not considered here. Further, this article only examines intentional creative production; digital media users' unintended production of valuable audience attention or marketing data is not considered here. Why focus on this creative, intentional, and public subset of digital labour? Because, as I explain later, these digital creatives constantly navigate tensions between personal fulfillment, future career aspirations, and (self-)exploitation. In this respect, digital creatives offer fruitful points of comparison to interns in the media and cultural industries.

\section{Methodological Considerations}

In my survey of the literature on the motivations and experiences of media and cultural industries interns, I specifically examine interns' experiences in mass media, the arts, journalism, public relations, and advertising -industries and institutions that all produce and circulate texts for public consumption. Previous research has attended more to the internship experiences of journalism, public relations, and advertising students and less to those in entertainment media and the arts; however, internship experiences across these industries and institutions are consistent enough to consider together.

To compose this thematic survey, I began by reviewing the relevant internship literature and identifying salient themes and sub-themes, such as "hands-on experience," "networking," "menial work," and "initiative." I had no illusions that these themes emerged from the data (as some grounded theorists claim). Instead, my interest in comparing internships to digital labour shaped my identification and understanding of salient themes. As I read, I reflected on theoretical constructs from the digital labour scholarship that resonated with interns' experiences, including socially recognized self-realization, hope labour, venture labour, aspirational labour, self-branding, and self-exploitation. These theoretical constructs helped me organize and make sense of the key themes I generated from the internship literature.

Ultimately, I organized this review around three key processes. First, I examine the nonmonetary motivations of interns and digital creative labourers. Both derive pleasure from carrying out work they consider meaningful and gaining approval from important others (whether peers, consumers, or supervisors). Second, I discuss the temporal logic through which interns and digital creatives rationalize their present work as future-oriented investments. These investments operate on the assumption that "experience + exposure = employment opportunities." Third, I reflect on the exploitative and self-exploitative potential of internships and digital creative labour. Both groups report actively pouring themselves into their work, even if that work can, at times, be menial, demanding, and offer little-to-no pay. Such selfexploitation may seem a choice; however, oversupplied labour markets make this fertile ground for coercion, particularly for those early in their career trajectories.

Given this review's reliance on existing internship research, it is important to highlight some of that literature's characteristics and limitations. With the exception of a few recent, critical interventions (e.g., Neff and Arata 2007, Frenette 2013; Siebert and Wilson 2013), I was struck by interns' glowing reviews of their experiences (e.g., Beard and Morton 1999; Beebe, Blaylock and Sweetser 2009; Getz 2002; Gugerty 2011; Hilt and Lipschultz 1996; Schambach and Dirks 2002). This may be explained, in part, as a function of how researchers gather internship accounts. Faculty often collect survey, interview, or focus group data from interns they supervise (e.g., Beard 1997; Beard and Morton 1999; Forde and Meadows 
2011; Schambach and Dirks 2002), and some also rely on interns' journals or site supervisors' evaluations (e.g., Barber 1987; Forde and Meadows 2011; Gugerty 2011; Getz 2002). It is unsurprising that such approaches produce favourable accounts of internships; students, faculty, and employers can each have vested interests in positively portraying these experiences. Further, existing internship research often pursues "administrative" rather than "critical" goals (Lazarsfeld 1941). That is, researchers aim to assess and improve student satisfaction with internship experiences, rather than interrogate the role of internships in reproducing or challenging power asymmetries (e.g., Beard and Morton 1999; Beebe, Blaylock and Sweetser 2009; Daugherty 2011). Students may indeed be satisfied with their internships; however, administrative goals can also blind researchers to the more troubling dynamics of internships. In fact, some literature reviews highlight the potential benefits of internships while giving little-to-no attention to their costs (e.g., Beard and Morton 1999; Schambach and Dirks 2002). Finally, many studies make a questionable leap in suggesting that students' assessments of internships are evidence of their value. Coll and Kalnins (2009) explain that while it is common to study interns' perceptions of personal and professional growth, those perceptions are not necessarily evidence of actual growth (e.g., skill development, crystallization of personal and professional values, employability).

These issues notwithstanding, the existing internship literature provides insightful accounts of students' experiences (or at least students' perception of their internships, as gathered by their faculty supervisors). The following review synthesizes this literature, draws comparisons between internships and digital creative labour, and uses digital labour theories to organize and make sense of interns' reported experiences.

\section{Internships as Meaningful Work}

Ursula Huws (2013) describes labour in its "quintessential form" as activity "carried out directly for a capitalist employer by a worker who is dependent on this labour for subsistence" (84). It is the worker's dependence on money to survive that allows capitalists to derive more value from one's labour time than wages account for, driving both profits and class antagonisms. Much digital creative labour operates on these terms; waged and salaried creatives work so they can earn money to subsist. Digital media have also contributed to a boom in freelance creative work, which is executed on a piecework basis, but is no less exploitative (Cohen 2012).

That said, creative labourers (digital or otherwise) often undertake their work for reasons over and above a paycheck. With its focus on symbol-making and the communication of experience, this work is often pleasurable, satisfying intrinsic motivations for creativity and identification. They also typically enjoy levels of creative and professional autonomy rarely seen in other forms of work (Gill 2002; Hesmondhalgh and Baker 2011; Neff 2012; Ross 2003). Indeed, firms in the media and cultural industries recognize that a degree of autonomy for creative workers is necessary if they are to produce texts that will satisfy consumers' fickle tastes and cultural expectations about creative independence (Hesmondhalgh 2007; Ryan 1992). Digital media have intensified and complicated these processes (Gill 2002; Neff 2012; Ross 2003). Andrew Ross (2003) explains how digital media consultancies in New York City's Silicon Alley attracted talent and piqued their creative urges through fun, free, collaborative, and exciting "no collar" work that, at times, looked more like play. This work came with occupational hazards, however, including a tendency toward self-exploitation. In exchange, though, digital creatives exercised a degree of autonomy conducive with the pursuit of creativity, authenticity, and productivity. In these ways, digital creative labour promises opportunities to "do what you love"-an orientation to work that Miya Tokumitsu (2014) calls the "unofficial work mantra of our time." Cultural representations of digital labour reinforce this mythology (Gill 2002; Neff, Wissinger and Zukin 2005).

Creativity's pleasures are also pronounced in digital peer production. In countless online communities, individuals come together to collaboratively produce and freely distribute socially useful products and services, such as encyclopedia entries, software, and citizenjournalism. Contributors do so primarily for personal and social reasons rather than financial 
compensation (Benkler 2006; Shirky 2010). This volunteerism satisfies creators' personal desires to autonomously pursue mastery in a given area. Social motivations-particularly peer recognition-tend to reinforce those personal motivations (Arvidsson 2008; Shirky 2010). As Adam Arvidsson (2008) says of peer producers, "It is not enough for me to know that [I have done excellent work]. I need a community of people whom I recognize as my peers to recognize this fact in turn" (332). Arvidsson refers to these mutually reinforcing social and personal motivations as "socially recognized self-realization" (ibid., 332), and numerous studies have identified this as a primary motivation for digital peer producers (e.g., Daugherty, Eastin and Bright 2008; Kuehn and Corrigan 2013; Oreg and Nov 2008; Shao 2009). Corporations that seek to harness digital peer producers' passion and creativity must also acknowledge and work to satisfy these motivations (Baker 2008; Murdock 2011). As Detlev Zwick et al. (2008) explain, "the ideological recruitment of consumers into productive co-creation relationships hinges on accommodating consumers' needs for recognition, freedom, and agency" (185).

Like professional creatives, media and cultural industries interns do want to be paid while completing their internships (Beebe, Blaylock and Sweetser 2009; Filak and Pritchard 2008); however, students also undertake internships for extra-monetary reasons. Catherine Gugerty (2011) argues that interns engage in a constant pursuit of "meaningful work," and students assign particular significance to practical experiences that are both consequential and afford a degree of autonomy and responsibility (Beard 1997; Daugherty 2011; Getz 2002; Gugerty 2011; Siebert and Wilson 2013).

First, students value internships that are practical in that they provide opportunities for "hands-on" work experiences in "real world" professional contexts (Beard 1997; Beebe, Blaylock and Sweetser 2009; Daniel and Daniel 2013; Daugherty 2011; Filak and Pritchard 2008; Getz 2002; Gugerty 2011; Hilt and Lipschultz 1996; Schambach and Dirks 2002; Siebert and Wilson 2013). These phrases_-"hands-on" and "real world"-signify interns' elevation of "authentic" work experiences over other forms of professional development, including classroom learning (which is not the "real world") and workplace observation (which may be part of an internship, but is not "hands-on"). It is worth noting that "authenticity" and "the real" are sought-after aesthetics in digital creative labour, from reality TV and fashion magazines to blogs and YouTube (Duffy 2013, 2015; Hesmondhalgh and Baker 2011). Cynically, interns' emphases on "real world" work can be seen (like reality TV) as the shrewd marketing of authenticity; such experiences signal one's genuine workplace-readiness to potential employers.

There is good reason to believe, though, that interns' emphasis on authenticity is more than just a means to an end. Existing research indicates that media and cultural industries interns associate hands-on learning with greater levels of self-esteem and confidencefeelings that are accentuated when they have the time and training to see a project through to fruition (Beard 1997; Daugherty 2011; Forde and Meadows 2011; Gugerty, 2011; Siebert and Wilson 2013). In other words, interns may achieve a sense of self-realization from the process and end-product of their "real world" work. To the extent that interns self-select into organizations that align with their personal passions and professional aspirations, this should not be surprising. Like digital creative labourers, they are pursuing mastery in their chosen field-even if that pursuit is at an introductory phase.

If there is a disjuncture here between the potential for self-realization in digital creative labour compared to internships, it is in the former's emphasis on the communication of experience and the latter's emphasis on learning-by-doing. Digital creative labour does present relatively unique possibilities for creativity and identification; however, learning can also be exciting and satisfying. In fact, journalists and documentary filmmakers report that learning about their subject matter can be deeply gratifying (Hesmondhalgh and Baker 2011). While acknowledging the potential pitfall of mistaking students' perceptions for actual learning, media and cultural industries interns do report extensive learning from their internships. In fact, it is not uncommon for students to describe their internships as the most important learning experience in their college career, and some go as far as to say it trumps their college learning, cumulatively (Gugerty 2011; Moore 2000). To the extent that learning-by-doing can be 
intrinsically satisfying, these reports would indicate substantial pleasures from interns' work experiences.

Second, media and cultural industries interns value effective on-the-job supervision (Beard 1997; Beard and Morton 1999; Beebe, Blaylock and Sweetser 2009; Daugherty 2011; Gugerty 2011). Fred Beard and Linda Morton (1999) found that supervision quality was the "most important single predictor" of what advertising and public relations students consider a "good internship" (50). Like their emphasis on authenticity, interns' attention to supervision can be seen as a shrewd calculation. Supervisors are (potentially) central to interns' future employment. They can provide access to marketable training and professional networks, and they can vouch for an intern's employability or even extend a job offer.

Interns' interactions with their supervisors can be meaningful in their own right, though. Gugerty (2011) explains that "site supervisors who provide interns with specific directions and examples, some autonomy and independence, and constructive feedback influence positive internship outcomes" (68). Much as digital creative labourers derive satisfaction from the autonomous pursuit of mastery (Arvidsson 2008; Shirky 2010), supervisors that can strike this balance between training (mastery) and trust (autonomy) stand to maximize the selfrealization their interns derive from hands-on work experiences. Take, for instance, Emma Daugherty's (2011) theme of "willingness" in interns' descriptions of "good site supervisors." Such supervisors are "willing to help the intern get the most out of the experience" and "willing to let you try and fail and learn" (473). Furthermore, supervisors that provide feedback offer more than training; they are also an intern's "audience." When interns execute meaningful, hands-on work, they turn to their supervisors for approval and feedback-for social recognition. In peer production, Clay Shirky (2010) describes a "feedback loop" between social recognition (whether from consumers or peers) and the personal satisfactions of creative processes. Social recognition makes creativity more satisfying. Similarly, supervisor feedback may amplify the meaningfulness of interns' hands-on work experiences.

There are practical limits to supervisors' "willingness," though. Professional standards and organizational imperatives mean that supervisors only have so much time for training and flexibility for failure (Frenette 2013; Daugherty 2011). These dynamics bear similarity to the "relative autonomy" long institutionalized in professional creative labour (Hesmondhalgh 2007; Ryan 1992) and celebrated by many digital creatives (Gill 2002; Neff 2012; Ross 2003). In these fields, a degree of autonomy for workers is commonly seen as a necessary condition for producing work that satisfies one's creative urges and that resonates with audiences-whether consumers or peers; however, that autonomy is ultimately constrained by management's control over productivity targets and the eventual marketing of creative works. Likewise, interns may pursue and derive satisfaction from hands-on work under effective supervision, but those processes unfold within an organizational context that can constrain practical opportunities for training and trust.

In short, people like getting better at things they care about on their own terms and receiving social recognition from important others for doing so. Both digital creative labour and internships offer opportunities for satisfying these desires. Socially recognized self-realization does not fully explain the motivations and experiences of either digital creatives or interns, though. Students also participate in internships as a means of positioning themselves for future employment opportunities in media and cultural industries. The following section looks at both internships and digital creative labour as future-oriented investments.

\section{Internships as Braggable Investments}

Digital creative labourers derive pleasure from creating and sharing for its own sake. In the Web 2.0 era, though, people increasingly view their voluntary creative endeavors as "investments" in experience and exposure that may translate, one day, into paid employment (Brabham 2008; Deuze 2007; Kücklich 2005; Postigo 2007). Success in this model hinges on one's ability to build a "networked reputation" (Deuze 2007). For instance, some SB Nation sports bloggers and Yelp! consumer reviewers told Kathleen Kuehn and myself (Kuehn and Corrigan 2013) that they see their work as a means of gaining creative experience, develop- 
ing their portfolios, building an audience for their work, and making strategic industry connections. Paid opportunities would follow-they hoped. We refer to these investments as "hope labor"- "un- or under-compensated work carried out in the present, often for experience or exposure, in the hope that future employment opportunities may follow" (ibid., 9). Similarly, Brooke Duffy (2015) found that fashion bloggers engage in "aspirational labor," "a highly gendered, forward-looking, and entrepreneurial enactment of creativity that ... hold[s] the promise of social and economic capital" (1).

This investment logic is not restricted to peer production. The high supply of aspiring professional creators has long contributed to precarity in cultural labour markets (Miège 1989). And in recent decades, neoliberal policies, corporate flexible accumulation strategies, and digital technologies have all contributed to greater employment uncertainty for creative workers and a shift of risk to individuals (Gill 2002; Harvey 2006; Hearn 2008; Neff 2012). Amid the precarity of their "project-based work" (Gill 2002), creatives organize themselves into "portfolio careers" (Flew and Cunningham 2010), where one's track record and industry connections are leaned on to secure employment on the next project (Ursell 2000; McRobbie 2002). The professional importance of social networks has also given rise to highly individual and instrumental social relations that Andreas Wittel (2001) calls "network sociality." This is pronounced in digital creative labour. During the volatile late-1990s dot-com boom, new media professionals in New York City's Silicon Alley managed risk by investing in themselves and the companies where they worked, a process Gina Neff (2012) theorizes as "venture labor." Workers deferred compensation through stock options, spent off-hours time at industry networking events, and sought to develop or hone their skills. They made these investments in an effort to sustain, propel, and capitalize on their companies' (potential) successes, but also as a hedge against industry uncertainty. Should one's specific company fail, Silicon Alley workers saw their skills (i.e., experience) and networks (i.e., exposure) as assets that would hasten their transition to another firm.

Students also rationalize their (often unpaid) internships in media and cultural industries as future-oriented investments, connecting their internship experiences to employment aspirations (Daniel and Daniel 2013; Daugherty 2011; Frenette 2013; Getz 2002; Gugerty 2011; Neff and Arata 2007; Siebert and Wilson 2013). For example, Daugherty (2011) found that public relations interns seek both "internal immediate rewards" and "external future rewards":

The internal immediate rewards included skill acquisition (writing, editing, professional experience in social media, production of printed materials), obtaining real-world experience, getting class credit to graduate, discovering if the field is for them, and gaining a better understanding of the field. The external future rewards were to make contacts to get a good job, get hired by their site supervisor, and develop a portfolio or work samples that will help them get a position. (427)

This excerpt illustrates that students pursue internships for meaningful, extra-monetary reasons (e.g., "real-world experience," "understanding of the field") and as future-oriented investments in their employment prospects (e.g., to "get a good job"). Moreover, the excerpt demonstrates that-like hope, aspirational, and venture labourers-interns employ an "experience + exposure $=$ employment opportunities" calculus in rationalizing their internships. "Work samples" and "contacts" were presumed to lead to job opportunities. On the face of it, this investment logic is compelling. Given the tendency toward portfolio careers in media and cultural industries, aspiring creatives face a "career progression paradox" (O'Mahony and Bechky 2006, 919); they need a track record and industry connections to get work, but they need work experience to acquire these assets. If one hopes to get and keep work in the media and cultural industries, it may make sense to undertake an internship where, even if unpaid, one can develop the skills and professionalism employers desire, while constructing a resume or portfolio that evinces those qualities. Moreover, through those experiences, one can get exposure to an office or supervisor that could potentially lead to a job offer at that organization or to work at another organization via networking and professional recommendations. 
Interns' characterization of their experience as "something you can put on your resume" (Gugerty 2011,30 ) demonstrates that such experiences have an important discursive quality. Students see strategic marketing value in what internships can "say" or "signal" to potential employers about their employability (Daugherty 2011; Frenette 2013; Getz 2002; Gugerty 2011). In this manner, internships function as a form of "self-branding" (Hearn 2008)-the process through which individuals construct and project a professional image to colleagues, clients, and current and future employers. Alison Hearn (2008) has argued that in flexible, networked economies, individuals strategically "brand" themselves "to rhetorically persuade employers of [their] competitive viability" (214). Again, a temporal, investment logic is at play. The self-branding process is "purely rhetorical; its goal is to produce cultural value and, potentially, material profit" (ibid.,198). Personal branding "gurus" such as Stedman Graham, Tom Peters, and Peter Montoya encourage individuals to think of themselves as "products" to be marketed to their "customers" (i.e., potential employers or clients). Aspiring professionals identify their most valuable skills and attributes and then communicate those "braggables" to their "target market" (ibid., 205).

Internships can be thought of as proxies for one's "braggable" skills and attributes. As one intern told Gugerty (2011), "I feel like people are impressed when I tell them I'm interning at [agency name]" (31). Here, the specific activities of an internship are not as important as the message that an internship conveys about the intern to potential future employers. As Perlin (2012) explains, internships function as a "signaling" mechanism for employers: "even if their exact content remains murky, [internships] signal a go-getter applicant, already fluent in office culture (and possibly in industry culture), able to take on a new role immediately with less time and investment from the firm" (182). Experimental research underscores the importance firms place on internship experiences. When sent the same resumes with and without internships listed, employers were significantly more likely to take positive action on an application (e.g., holding onto a resume, initiating an interview) when the applicant had completed an internship (Taylor 1988; Nunley, Pugh, Romero and Seals 2014). As internships become more common among graduates in media and cultural industries some students are stringing together multiple internships to distinguish their applications, branding themselves as the gogetters of the go-getters (Frenette 2013; Neidorf 2008).

Internships are not just a means of developing skills and professionalism or getting one's foot in the door and networking. They are also a means of discursively presenting one's self as an employable professional. There is a risk in this characterization, though. As "investments" and "opportunities," internships sound like a "smart move" undertaken by enterprising students, which implies that interning is an individual choice. But to the extent that internships are perceived as necessary for securing work in the media and cultural industries, that choice may be illusory, particularly for students without the resources to participate in unpaid internships. Students' lack of choice in pursuing internships and ambiguity about what internships should entail open the door to exploitation and self-exploitation.

\section{Internships as Ambiguous (Self-)Exploitation}

There is much debate over whether, and how, digital creative labour is "exploited" (Andrejevic 2009, 2012; Cohen 2012; Hesmondhalgh 2010; Hesmondhalgh and Baker 2011; Fish and Srinivasan 2012). Following Holmstrom (1997), Andrejevic (2012) describes capitalist exploitation as a two-part process, entailing (1) the extraction of surplus value through coerced labour and (2) a loss of control over one's productive activity (i.e., alienation). With respect to coercion, professional creatives depend on money from wages (or piecework payments or royalties) for their subsistence. This dependency produces a relationship wherein capitalists can pay workers less in wages than the full value their labour creates-a dynamic that is exacerbated by the excess supply of aspiring creatives. With respect to control, though, professional creatives can enjoy autonomy at work rarely seen among other labourers, such as factory workers (Hesmondhalgh 2007; Ryan 1992). This measure of freedom and independence is always relative and, ultimately, revocable through termination (Garnham 2006); however, this autonomy, paired with possibilities for creativity and identifi- 
cation, means that creative labourers can experience pleasures at work that are at odds with conventional notions of alienation and exploitation (Hesmondhalgh and Baker 2011).

Digital creative labour is no workers' paradise, though (Gill 2002; Neff 2012; Ross 2003). Amid this work's self-directed pleasures and relative autonomy, digital creative labourers can engage in "self-exploitation"- "the worker drives herself or himself harder and harder in order to achieve excellence, further status and perhaps even to maintain the very freedom they have struggled to achieve in the first place" (Hesmondhalgh and Baker 2011, 226). Ross (2003) notes that Silicon Alley's "no collar" workers integrated the art world's "sacrificial labor" and bohemian lifestyle into commercial contexts, working extraordinary hours in sub-par conditions for deferred compensation while dispensing with any semblance of work-life balance. Hesmondhalgh and Baker $(2011,227)$ explain that creative labourers' "special bond" with their work and the "starving artist" myth make them particularly susceptible to such selfexploitation. In short, digital creatives may enjoy a degree of independence, but their labour is still coerced, and their pursuit of autonomy and creative pleasures may manifest as selfexploitation.

Whether or not digital peer production is exploitative is a murkier question. Tiziana Terranova (2000) describes online free labour as "simultaneously voluntarily given and unwaged, enjoyed and exploited" (74). As a labour of love-and perhaps as a route to satisfying future employment-it is not uncommon for peer producers to pour extraordinary time and effort into their creative endeavours. Web firms and marketers actively seek to appropriate those labours for commercial purposes (Baker 2008; Murdock 2011; Zwick et al. 2008); however, the appropriation of free labour is not necessarily exploitative (Andrejevic 2009; Hesmondhalgh 2010; Huws 2013). Most peer producers are not dependent on compensation from these creative labours for subsistence, and, as a labour of love, most would continue this work even if never paid. Further, peer producers typically enjoy wide creative latitude, as this is often the best way to maximize their time and effort absent the threat of termination (Corrigan 2012; Zwick et al. 2008). Thus, commercial firms do appropriate peer producers' unpaid creative labour, but not necessarily under the coercive, alienating dynamics of direct exploitation.

On the question of exploitation, internships appear, at first glance, to be more akin to digital peer production than professional creative labour. As long as an internship is not a graduation requirement, students can always choose not to participate. In fact, when one adds up costs for gas, tuition, and foregone compensation from a part-time job, participating in an internship may actually make subsistence more difficult in the short-run, especially if the internship is unpaid. Yet, if internships are all but necessary for entry into media and cultural industries careers, then the potential for exploitation is very real. Jim Frederick (1997) argues that the glamour and desirability of media and cultural industries work makes these firms hotbeds for intern exploitation. Indeed, the career information service Vault reports that unpaid internships are concentrated in political, media, and cultural industries (Jenkins 2003). Some internship supervisors admit that an important, if not primary, impetus for taking on interns is to get "free labour" or "extra hands" to relieve their individual or organizational workloads (Beard 1997; Frenette 2013; Siebert and Wilson 2013). Faced with few good options, arts interns state that they are "prepared to work up to a thousand hours for free to 'ingratiate themselves with the industry,' 'get their face noticed,' or 'get ahead'" (Siebert and Wilson 2013, 715). If experience and exposure are what interns are "paid" in, and their longrun subsistence as creatives necessitates acquisition of these resources, then we can see their unpaid or under-paid labour as the product of coercion.

The counter-argument is that learning is the basic rationale for internships rather than payment or even enhancing one's job prospects. This argument presumes that interns are learning something, though. Students do ascribe particular value to internships that offer meaningful, hands-on experiences, and effective supervision; however, not all internships deliver on this potential. Some interns describe their supervisors and other employees as "indifferent," "disinterested," and "unwilling" (Daniel and Daniel 2013; Daugherty 2011; Frenette 2013; Forde and Meadows 2011; Gugerty 2011; Siebert and Wilson 2013). Supervisors often expect interns to perform at a high level upon arrival. Others approach interns with a 
degree of "presumed incompetence" (Frenette 2013) - an assumption about interns in popular culture representations. Either way, supervisors complain about being too busy to spend time and energy training and mentoring interns that may only be around for a few months. And they also express concerns about assigning important work to interns with limited experience (Daniel and Daniel 2013; Frenette 2013; Daugherty 2011; Siebert and Wilson 2013).

Whether a function of practical workplace constraints or cultural assumptions about interns, some supervisors prefer that their interns observe rather than execute work, and what work supervisors do assign to interns can be menial (Barber 1987; Beard 1997; Daugherty 2011; Daniel and Daniel 2013; Frenette 2013; Getz 2002; Siebert and Wilson 2013). One music industry employee bluntly told Alexandre Frenette (2013) that interns were assigned "shit work" that needed to "get done." Susan Barber (1987) analyzed site supervisors' evaluation forms and found that interns most frequently executed "desk work," including "research," "administrative/clerical" work, and "client communication," such as answering phones. Interns also face the all-too-common problem of having nothing to do (Beard 1997; Daugherty 2011; Frenette 2013; Gugerty 2011). To try to keep interns busy, some supervisors assign long-term projects and "to-do" lists, but this often results in only more "busy work" (Beard 1997; Frenette 2013; Gugerty 2011). Interns' reports of menial work and indifferent/unwilling supervisors suggest that they are not just coerced into unpaid or under-paid labour, but that they can also face an alienating loss of control over their work-exploitation's second criteria. Indeed, some public relations interns reported that they "felt powerless to get enough work and experience" and "to be assigned meaningful tasks" (Daugherty 2011, 472).

Interns report dealing with this powerlessness in one of two ways. First, to break out of the cycle of downtime and menial tasks, interns are presented with a "vague promise" (Frenette 2013): should they perform mundane tasks well, they could expect more meaningful work and responsibility in the future. In other words, interns are encouraged to self-exploit: to assign duties to themselves, to ask for more tasks, or to pitch work ideas to supervisors (ibid.). Expectations that interns be "proactive," show "initiative," and have a "positive attitude" appear regularly in the accounts of interns and their supervisors (Beard 1997; Daniel and Daniel 2013; Daugherty 2011; Frenette 2013; Gugerty 2011; Forde and Meadows 2011; Frenette 2013; Neff and Arata 2012). There is a discursive component to these processes. Drawing on Michael Hardt and Antonio Negri's (2000) concept of "affective labor," Gina Neff and Giovanni Arata (2012) call interns' demonstrations of initiative "performative passion"- "displays of enthusiasm for the tasks at hand-even mundane ones-and the savvy to figure out which tasks to undertake without supervision" (14).

The second tactic interns use to deal with their powerlessness is assigning meaning and value to otherwise menial work (Beard 1997; Forde and Meadows 2011; Getz 2002). As Gugerty (2011) explains, "The differentiation between meaningful and menial work was often blurred in students' minds, confused by their desire to feel productive and appreciated" (55). With photocopying and fetching coffee as the low bar, interns can find a silver lining in nearly anything they do. Sometimes this is accomplished by elevating the importance of menial tasks. As one intern bragged to Gugerty (2011), "I sat at the front desk and everyone had to come through me" (57-58). In other cases, students ascribe a deeper significance to otherwise disappointing experiences; the internship offered a window on the "real world," a test of one's determination, or insight that a particular field isn't for them (Forde and Meadows 2011; Getz 2002). On this basis, John Getz (2002) argues that "even a miserable internship has its lessons to teach"; however, Perlin (2012) cautions against taking this line of thinking too far: "many educators have never seen an internship they didn't like-one supposedly learns as much from terrible experiences as from good ones" (94).

Frenette (2013) and Perlin (2012) both argue that interns' experiences are deeply ambiguous. Much as work and play are often intertwined in digital creative labour, internships operate somewhere between education and employment, the present and future, and monetary and non-monetary forms of compensation. In this ambiguous, "elastic role"-with multiple, competing interpretations about what interns should do and achieve-interns assume responsibility for making the most of the experience (Frenette 2013). But interns do not control access to the meaningful, hands-on experiences that they value and that may be important 
to their future employment prospects-their supervisors do. This combination of ambiguity and dependency makes internships fertile ground for exploitation and self-exploitation. Acts of initiative and performative passion-even for menial tasks—provide interns with a sense of control and may persuade a supervisor to assign more meaningful work; however, what appears an autonomous choice can mask the internship's exploitative relations of coercion and alienation. Media and cultural industries interns may have little choice but to undertake menial tasks or to invest meaning in the menial: entry into their chosen field may depend on that internship.

\section{Conclusion: Meaning, Temporality, and Ambiguity}

In this article, I provided a thematic review of the scholarly literature on the motivations and experiences of media and cultural industries interns. To summarize, students generally report positive internship experiences, and they consider internships particularly meaningful when supervisors provide practical training and trust interns to execute hands-on work. Students also undertake internships as future-oriented investments in their skills, professional networks, and personal brands. This makes sense, as work experience and networking are increasingly prerequisites for employment in these popular industries. But this dependency, paired with ambiguity about what internships should entail, exposes interns to exploitation and self-exploitation. Unpaid, menial, and poorly supervised internships do occur. To earn supervisors' trust and access to more meaningful, professionally promising work responsibilities, interns are expected to demonstrate initiative and perform menial tasks with passion. Or, interns simply invest meaning in menial tasks.

This article juxtaposed the motivations and experiences of media and cultural industries interns with those of digital creative labourers-both professionals and peer producers. Interns place greater emphasis on learning than digital creatives do; however, both groups derive satisfaction from developing their skills under conditions of relative autonomy and from receiving social recognition from an audience of important others (whether customers, peers, or supervisors). Interns and digital creative labourers both also view their work as futureoriented investments, and they make those investments under the assumption that "experience + exposure $=$ employment opportunities." Finally, both groups operate under conditions conducive to exploitation and self-exploitation. They are dependent on work experience and networking to launch and propel their careers, yet this coercive potential is often masked by participants' enthusiasm for their work. The ambiguity of internships-like the ambiguity between work and play in creative labour-means that responsibility falls on the intern to make the most out of the experience.

While the existing internship literature is instructive, internships are still a nascent research area ripe for critical investigation. The literature's most glaring gap concerns the role of race, class, gender, and other intersecting social stratifications on internship experiences, as well as the impact of internships on those social stratifications. Such oversight is not unique to internship studies, of course. Digital labour researchers only recently began correcting their area's own lack of attention to gender (e.g., Banks and Milestone 2011; Duffy 2015; Gill 2002; McRobbie 2002). Some key themes from the current review, including interns' elevation of "hands-on work" and "initiative," may offer fruitful entry points for interrogating the socio-cultural assumptions embedded in internship experiences: Are internships implicitly racialized, classed, or gendered? And what are the social implications of those assumptions? In addition to the substance of internships, critical scholars should also interrogate asymmetries in access to internships. Charles Murray (2012) has called unpaid internships "career assistance for rich, smart children," and over-reliance on unpaid internships in media and cultural fields may narrow the range of public voices and perspectives (Neff and Arata 2007). Such critiques await further study.

As critical internship studies interrogates these and other processes, I argue-based on the preceding review-that researchers will need to account for three key dynamics in interns' experiences: meaning, temporality, and ambiguity. First, critical scholars will rightfully critique the under-compensation, menial work, and lackluster supervision of exploitative in- 
ternships; however, each of these concerns hinges on an assumption about what a "good internship" is (as well as "good work" more generally). Students have their own ideas about what makes an internship meaningful (e.g., "willing" supervisors trusting them with "handson" work). If we fail to attend to the meanings interns ascribe to their experiences, we will blind ourselves to the ways in which this institution's exploitative and self-exploitative dynamics are rationalized ideologically. Again, interns don't undertake menial work for the heck of it; they do so under a vague promise that more meaningful, professionally promising responsibilities will follow. Attention to meaning will also be important in envisioning and building more fair, just, and beneficial internship structures.

Second, much of the existing internship literature seeks to answer a single question: "What do students find satisfying about internships?" The problem with this question is not only that it focuses narrowly on benefits, but that it also misses the temporal relationship between interns' present experiences and their future employment aspirations. Researchers must seek to make sense of internship experiences within the career structures of their respective industries. Indeed, this is how interns rationalize their work-as future-oriented investments. For instance, Neff and Arata (2007) argue that internships may function to socialize students into post-industrial work. Such a line of inquiry also opens the door to comparative analysis: how do internship experiences in media and cultural industries differ from those in other, less glamorous and network-driven industries? Further, few existing studies followup with interns (and non-interns) to evaluate the impact of those experiences on their personal and professional lives (Neidorf 2008; Taylor 1988). Such studies are methodologically challenging, but without longitudinal and comparative data, the investment logic of internships remains a matter of faith. Even if internships do lead to jobs, we should not assume that they are a fair and just way to organize labour markets. Some paid employees point the finger at unpaid internships and other "atypical labour" (e.g., freelancing) for deteriorations of pay and security (Gollmitzer 2014; Siebert and Wilson 2013). These assertions deserve further empirical study.

Finally, critical internship studies needs to continue to wrestle with the ambiguity of internships. Interns are not yet employees, but not fully students. They receive compensation, but it may not be in the form of a fair wage. Their roles and responsibilities are vague, as is their route to meaningful work and future employment. Internships are part learning experience, part resume workshop, part networking event, part unpaid labour. It is in the ongoing negotiation of this ambiguity by students, faculty, and supervisors that the promise and depravity of internships play out.

\section{References}

Andrejevic, Mark. 2009. Exploiting YouTube: Contradictions of User-Generated Labor. In The YouTube Reader, 2nd ed., edited by Pelle Snickars and Patrick Vonderau, 406-423. Stockholm: National Library of Sweden.

Andrejevic, Mark. 2012. Exploitation in the Data Mine. In The Internet and Surveillance: The Challenges of Web 2.0 and Social Media, edited by Christian Fuchs, Kees Boersma, Anders Albrechtslund and Marisol Sandoval, 71-88. London and New York: Routledge.

Arvidsson, Adam. 2008. The Ethical Economy of Customer Coproduction. Journal of Macromarketing 28 (4): 326-338.

Baker, Stephen. 2008, December 28. Will Work for Praise: The Web's Free-Labor Economy. Bloomberg Businessweek. Accessed November 15, 2014. http://www.businessweek.com/stories/200812-28/will-work-for-praise-the-webs-free-labor-economybusinessweek-business-news-stockmarket-and-financial-advice.

Banks, Mark and Katie Milestone. 2011. Individualization, Gender and Cultural Work. Gender, Work \& Organization 18 (1): 73-89.

Barber, Susan. 1987. What Media Internships Really Offer Students! (Or Matching Skill Use with the Right Agency). Journal of Cooperative Education 23 (3): 63-71.

Beard, Fred. 1997. Inside the Advertising and Public Relations Internship. Paper presented at the Annual Conference of the Association for Education in Journalism and Mass Communication, Chicago, IL. Accessed June 19, 2014. http://list.msu.edu/cgibin/wa?A2=ind9710A\&L=AEJMC\&P=R24962. 
Beard, Fred and Linda Morton. 1999. Effects of Internship Predictors on Successful Field Experience. Journalism and Mass Communication Educator 53 (4): 42-53.

Beebe, Ashley, Abigail Blaylock and Kaye D. Sweetser. 2009. Job Satisfaction in Public Relations Internships. Public Relations Review 35 (2): 156-158.

Benkler, Yochai. 2006. The Wealth of Networks: How Social Production Transforms Markets and Freedom. New Haven, CT: Yale University Press.

Benkler, Yochai and Helen Nissenbaum. 2006. Commons-Based Peer Production and Virtue. Journal of Political Philosophy 14 (4): 394-419.

Brabham, Daren C. 2008. Crowdsourcing as a Model for Problem Solving: An Introduction and Cases. Convergence 14 (1): 75-90.

Cohen, Nicole S. 2008. The Valorization of Surveillance: Towards a Political Economy of Facebook. Democratic Communiqué 22 (1): 5-22.

Cohen, Nicole S. 2012. Cultural Work as a Site of Struggle: Freelancers and Exploitation. tripleC 10 (2): 141-155.

Coll, Richard K. and Tatiana Kalnins. 2009. A Critical Analysis of Interpretive Research Studies in Cooperative Education and Internships. Journal of Cooperative Education \& Internships 43 (1): 113.

Corrigan, Thomas F. 2012. Manufacturing Sports Blogs: The Political Economy and Practice of Networked Sports Blogging. Ph.D. dissertation, Pennsylvania State University.

Daniel, Ryan and Leah Daniel. 2013. Enhancing the Transition from Study to Work: Reflections on the Value and Impact of Internships in the Creative and Performing Arts. Arts \& Humanities in Higher Education 12 (2-3): 138-153.

Daugherty, Emma L. 2011. The Public Relations Internship Experience: A Comparison of Student and Site Supervisor Perspectives. Public Relations Review 37 (5): 470-477.

Daugherty, Terry, Matthew S. Eastin and Laura Bright. 2008. Exploring Consumer Motivations for Creating User-Generated Content. Journal of Interactive Advertising 8 (2): 16-25.

Deuze, Mark. 2007. Media Work. Cambridge, MA: Polity.

Duffy, Brooke E. 2013. Manufacturing Authenticity: The Rhetoric of "Real" in Women's Magazines. The Communication Review 16 (3): 132-154.

Duffy, Brooke E. 2015. The Romance of Work: Gender and Aspirational Labour in the Digital Culture Industries. International Journal of Cultural Studies. Accessed February 25, 2015. DOI: 10.1177/1367877915572186.

Filak, Vincent F. and Robert S. Pritchard. 2008. Fulfilling Psychological vs. Financial Needs: The Effect of Extrinsic Rewards on Motivation and Attachment to Internship Opportunities. Paper presented at the Annual Conference of the Association for Education in Journalism and Mass Communication. Chicago, IL. Accessed June 19, 2014. http://citation.allacademic.com/meta/p mla apa research_citation/2/7/2/3/1/p272318 index.html.

Fish, Adam and Ramesh Srinivasan. 2012. Digital Labor is the New Killer App. New Media \& Society 14 (1): 137-152.

Flew, Terry and Stuart Cunningham. 2010. Creative Industries After the First Decade of Debate. The Information Society 26 (2): 113-123.

Forde, Susan and Michael Meadows. 2011. Industry Placements in Journalism Education: Exploring Enhanced Learning and Professional Growth for Interns. JRE Journal. Accessed June 19, 2014. http://jrejournal.com/ojs-2.3.7/index.php/jre/article/view/12.

Frederick, Jim. 1997. Internment Camp: The Intern Economy and the Culture Trust. The Baffler 9. Accessed June 19, 2014. http://www.thebaffler.com/past/internment_camp.

Frenette, Alexandre. 2013. Making the Intern Economy: Role and Career Challenges of the Music Industry Intern. Work and Occupations 40 (4): 364-397.

Fuchs, Christian. 2012. Dallas Smythe Today-The Audience Commodity, the Digital Labour Debate, Marxist Political Economy, and Critical Theory. Prolegomena to a Digital Labour Theory of Value. tripleC 10 (2): 692-740.

Fuchs, Christian and Marisol Sandoval. 2014. Digital Workers of the World Unite! A Framework for Critically Theorising and Analysing Digital Labour. tripleC 12 (2): 486-563.

Garnham, Nicholas. 2006. Contribution to a Political Economy of Mass-Communication. In Media and Cultural Studies: Keyworks, 2nd ed., edited by Meenakshi G. Durham and Douglas. M. Kellner, 201-229. Malden, MA: Blackwell.

Getz, John E. 2002. Journalism Students' Perceptions of the Value of Internships. Paper presented at the Annual Conference of the Association for Education in Journalism and Mass Communication. 
Miami Beach, FL. Accessed June 19, 2014. http://list.msu.edu/cgibin/wa?A2=ind0209A\&L=AEJMC\&P=R11883.

Gill, Rosalind. 2002. Cool, Creative and Egalitarian? Exploring Gender in Project-Based New Media Work in Europe. Information, Communication \& Society 5 (1): 70-89.

Gollmitzer, Mirjam. 2014. Precariously Employed Watchdogs? Perceptions of Working Conditions Among Freelancers and Interns. Journalism Practice. Accessed March 10, 2014. DOI: 10.1080/17512786.2014.882061.

Gugerty, Catherine A. 2011. Internships in Public Relations and Advertising: The Nature of the Experience From the Student's Perspective. Master's thesis, University of South Florida.

Hardt, Michael and Antonio Negri. 2000. Empire. Cambridge, MA: Harvard University Press.

Harvey, David. 2006. The Limits to Capital. London and New York: Verso.

Hearn, Alison. 2008. "Meat, Mask, Burden": Probing the Contours of the Branded "Self." Journal of Consumer Culture 8 (2): 197-217.

Hesmondhalgh, David. 2007. The Cultural Industries, $2^{\text {nd }}$ Edition. Los Angeles, CA: Sage.

Hesmondhalgh, David. 2010. User-Generated Content, Free Labour and the Cultural Industries. ephemera 10 (3/4): 267-284.

Hesmondhalgh, David and Sarah Baker. 2011. Creative Labour: Media Work in Three Cultural Industries. London \& New York: Routledge.

Hilt, Michael L. and Jeremy Harris Lipschultz. 1996. Broadcast Newsroom Hiring and Career Preparation. Journalism \& Mass Communication Educator 51 (1): 36-43.

Holmstrom, Nancy. 1997. Exploitation. In Exploitation: Key Concepts in Critical Theory, edited by Kai Nelson and Robert Ware, 81-102. Atlantic Highlands: Human Press International.

Huws, Ursula. 2013. The Underpinnings of Class in the Digital Age: Living, Labour, and Value. Socialist Register 50: 80-107.

Jenkins, Chris L. 2003. Cost of Experience: Priceless Law School Graduate Waits Tables to Fund Unsalaried Dream Job. The Washington Post, July 1. Accessed May 26, 2015.

http://www.lexisnexis.com.libproxy.lib.csusb.edu/Inacui2api/results/docview/docview.do?docLinkInd $=$ true\&risb=21 T22078107275.

Kücklich, Julian. 2005. Precarious Playbour: Modders and the Digital Games Industry. The Fibreculture Journal 5. Accessed June 19, 2014. http://five.fibreculturejournal.org/fcj-025-precariousplaybour-modders-and-the-digital-games-industry/.

Kuehn, Kathleen and Thomas F. Corrigan. 2013. Hope Labor: The Role of Employment Prospects in Online Social Production. The Political Economy of Communication 1 (1): 9-25. Accessed June 19, 2014. http://academic.wwwss2.a2hosting.com/ojs/index.php/polecom/article/view/9.

Lazarsfeld, Paul F. 1941. Remarks on Administrative and Critical Communications Research. Studies in Philosophy and Social Science 9: 2-16.

Leadbeater, Charles and Paul Miller. 2004. The Pro-Am Revolution: How Enthusiasts are Changing our Economy and Society. London: Demos.

McRobbie, Angela. 2002. Clubs to Companies: Notes on the Decline of Political Culture in Speeded Up Creative Worlds. Cultural Studies 16 (4): 516-531.

Miège, Bernard. 1989. The Capitalization of Cultural Production. New York: International General.

Moore, Robert C. 2000. I Learned More Than In All of My Classes. ASJMC Insights. Winter/Spring. 13-16.

Mosco, Vincent and Catherine McKercher. 2008. The Laboring of Communication: Will Knowledge Workers of the World Unite? Lanham, MD: Lexington Books.

Murdock, Graham. 2011. Political Economies as Moral Economies: Commodities, Gifts, and Public Goods. In The Handbook of Political Economy of Communications, edited by Janet Wasko, Graham Murdock and Helena Sousa, 13-40. Malden, MA: Blackwell Publishing.

Murray, Charles A. 2012. Narrowing the New Class Divide. The New York Times, March 7. Accessed June 19, 2014. http://www.nytimes.com/2012/03/08/opinion/reforms-for-the-new-upper-class.html.

Neff, Gina. 2012. Venture Labor: Work and the Burden of Risk in the Innovative Industries. Cambridge, MA \& London: The MIT Press.

Neff, Gina and Giovanni Arata. 2007. The Competitive Privilege of Working for Free: Rethinking the Roles that Interns Play in Communication Industries. Paper presented at the Annual Meeting of the American Sociological Association. Accessed June 19, 2014.

http://citation.allacademic.com/meta/p mla_apa_research_citation/1/8/3/9/6/p183960 index.html.

Neff, Gina, Elizabeth Wissinger and Sharon Zukin. 2005. Entrepreneurial Labor Among Cultural Producers: "Cool" Jobs in "Hot" Industries. Social Semiotics 15 (3): 307-334. 
Neidorf, Shawn M. 2008. Wanted: A First Job in Journalism-An Exploration of Factors that May Influence Initial Job-Search Outcomes for News-Editorial Students. Journalism \& Mass Communication Educator 63 (1): 56-65.

Nunley, John M., Adam Pugh, Nicholas Romero and R. Alan Seals. 2014. College Major, Internship Experience, and Employment Opportunities: Estimates from a Résumé Audit. Auburn University Department of Economics Working Paper Series. http://cla.auburn.edu/econwp/Archives/2014/2014-03.pdf.

O'Mahony, Siobhan and Beth A. Bechky. 2006. Stretchwork: Managing the Career Progression Paradox in External Labor Markets. Academy of Management Journal 49 (5): 918-941.

Oreg, Shaul and Oded Nov. 2008. Exploring Motivations for Contributing to Open Source Initiatives: The Roles of Contribution Context and Personal Values. Computers in Human Behavior 24 (5): 2055-2073.

Perlin, Ross. 2012. Intern Nation: How to Earn Nothing and Learn Little in the Brave New Economy. London: Verso.

Postigo, Hector. 2007. Of Mods and Modders: Chasing Down the Value of Fan-Based Digital Game Modifications. Games and Culture 2 (4): 300-313.

Ritzer, George and Nathan Jurgenson. 2010. Production, Consumption, Prosumption: The Nature of Capitalism in the Age of the Digital 'Prosumer.' Journal of Consumer Culture 10 (1): 13-36.

Ross, Andrew. 2003. No-Collar: The Humane Workplace and its Hidden Costs. New York, NY: Basic Books.

Ryan, Bill. 1992. Making Capital from Culture: The Corporate Form of Capitalist Cultural Production. Berlin and New York: Walter de Gruyter

Schambach, Thomas P. and Jim Dirks. 2002. Student Perceptions of Internship Experiences. Paper presented at the International Academy for Information Management (IAIM) Annual Conference. Accessed June 19, 2014. http://eric.ed.gov/?id=ED481733.

Scholz, Trebor, ed. 2013. Digital Labor: The Internet as Playground and Factory. New York \& London: Routledge.

Shao, Guosong. 2009. Understanding the Appeal of User-Generated Media: A Uses and Gratification Perspective. Internet Research 19 (1): 7-25.

Shirky, Clay. 2010. Cognitive Surplus: Creativity and Generosity in a Connected Age. New York: Penguin.

Siebert, Sabina and Fiona Wilson. 2013. All Work and No Pay: Consequences of Unpaid Work in the Creative Industries. Work, Employment and Society 27 (4): 711-721.

Taylor, Susan. M. 1988. Effects of College Internships on Individual Participants. Journal of Applied Psychology 73 (3): 393-401.

Terranova, Tiziana. 2000. Free Labour: Producing Culture for the Digital Economy. Social Text 18 (2): 33-58.

Tokumitsu, Miya. 2014. In the Name of Love. Slate. Accessed June 19, 2014. http://www.slate.com/articles/technology/technology/2014/01/do what you love_love_what_you_d o_an_omnipresent_mantra_that_s_bad_for_work.html.

Turow, Joseph. 2011. The Daily You: How the New Advertising Industry is Defining Your Identity and Your Worth. New Haven: Yale University Press.

Ursell, Gillian. 2000. Television Production: Issues of Exploitation, Commodification and Subjectivity in UK Television Labour Markets. Media, Culture \& Society 22 (6): 805-825.

Wittel, Andreas. 2001. Toward a Network Sociality. Theory, Culture \& Society 18 (6): 51-76.

Zwick, Detlev, Samuel K. Bonsu and Aron Darmody. 2008. Putting Consumers to Work: 'Co-Creation' and New Marketing Govern-mentality. Journal of Consumer Culture 8 (2): 163-196.

\section{About the Author}

Thomas F. Corrigan

Thomas F. Corrigan is an Assistant Professor of Mass Communication in the Department of Communication Studies at California State University, San Bernardino. His research examines the political economy of new media, particularly sports media, digital labour, and critical research methods. His work has been published in The Political Economy of Communication, Journalism: Theory, Practice, \& Criticism, Cultural Studies $<=>$ Critical Methodologies, International Journal of Sport Communication, and Journal of Sports Media. 